\title{
Psychologists' Knowledge of and Attitudes about Near-Death Experiences: Changes over Time and Relationship to Transpersonal Self-Concept
}

\author{
Cheryl Fracasso, M.S. \\ Saybrook University \\ Harris Friedman, Ph.D. \\ Walden University \\ M. Scott Young, Ph.D. \\ University of South Florida
}

\begin{abstract}
We conducted a comparison and extension of Walker and Russell's (1989) study of psychologists' knowledge of and attitudes about near-death experiences (NDEs). We used their Near-Death Phenomena Knowledge and Attitudes Questionnaire (NDPKAQ), consisting of one knowledge scale and two attitude scales, to explore possible changes over time. We also used the SelfExpansiveness Level Form-Transpersonal Scale (SELF-TS; Friedman, 1983) to explore the relationship of transpersonal self-concept with knowledge of and attitudes about NDEs. We randomly surveyed 84 psychologists listed in the Washington state National Register and obtained 18 completed responses $(61 \%$ male, $39 \%$ female; mean age 60 years; ethnicity unknown). The comparison of
\end{abstract}

Cheryl Fracasso, M.S., is currently pursuing a Ph.D. in Clinical Psychology at Saybrook University. She serves as adjunct faculty member for the University of Phoenix; Research Assistant at Saybrook University with Stanley Krippner, Ph.D.; and Associate Managing Editor of the International Journal of Transpersonal Studies. Harris Friedman, Ph.D., is a practicing clinical and organizational psychologist who was affiliated with Walden University at the time of the study; he now is Research Professor (Retired) of Psychology at the University of Florida, Professor Emeritus at Saybrook University, Senior Editor of the International Journal of Transpersonal Studies, and Associate Editor of The Humanistic Psychologist. M. Scott Young, Ph.D., is Research Assistant Professor in the Department of Mental Health Law and Policy at the University of South Florida. Correspondence regarding this article should be sent to Ms. Fracasso; email: cherylfracasso@hotmail.com. 
our NDPKAQ data with Walker and Russell's Illinois psychologists' data suggests psychologists' knowledge and attitudes about NDEs have remained unchanged over the past two decades $(p>.05)$. Two of the three NDPKAQ scale scores correlated significantly with the SELF-TS scores $(p=.03, .05)$, suggesting a positive relationship between transpersonal self-concept and knowledge of and attitudes towards NDEs. We discuss limitations of our results and implications of our findings for professional education and training on NDEs.

KEY WORDS: near-death experience, self-concept, transpersonal, education, training

Recent medical advances have greatly increased survival rates after accidents and diseases, which in turn have concomitantly increased near-death experiences (NDEs). For example, with improved resuscitation techniques, the average incidence of NDEs among people who have survived a close brush with death has been $35 \%$ in retrospective studies and $17 \%$ in prospective studies (Zingrone \& Alvarado, 2009 , p. 36). In addition, the public is increasingly exposed to NDEs through popular media, such as the recent National Public Radio series, The Science of Spirituality (see http://www.npr.org/templates/ story/story.php?storyId=110997741). Furthermore, clinical training on NDEs for U.S. physicians and nurses is increasing (Cunico, 2001; Greyson, 1997; Hayes \& Orne, 1990; Hayes \& Waters, 1989; Lawrence \& Duggal, 2001; McVoy, 1990; Moore, 1994; Sheeler, 2005; Thornburg, 1988). However, we know of no comparable efforts for helping mental health professionals keep up with the burgeoning knowledge related to NDEs. We located only one study, conducted over two decades ago, assessing NDE knowledge and attitudes in a sample of psychologists (Walker \& Russell, 1989). Consequently, we conducted a follow-up of that study to explore whether any changes had occurred since the original. We also extended the original study by including a transpersonal measure, hypothesizing that participants higher in transpersonal self-concept would know more about and hold more favorable attitudes toward NDEs, as we speculated that transpersonal self-concept could become a salient focus for training of mental health professionals to foster more openness to the worth of NDEs.

\section{Mental Health Implications of NDEs}

The results of many studies suggest that near-death experiencers (NDErs) often have negative post-NDE consequences that lead to di- 
agnoses of mental illness. For example, John Wren-Lewis (2004) found NDErs had increased rates of personal distress, and Linda Morris (1998; Morris \& Knafl, 2003) found evidence of increased depression. However, findings that on the surface might seem to indicate psychological problems could alternatively be interpreted as indicating the beginnings of positive psychological growth rather than psychopathological change. For example, S. Rozan Christian (2006) found NDErs had high divorce rates, but she attributed this outcome primarily to dramatic alterations in NDErs' lifestyles and values, which could signal either positive or negative changes.

Many authors have accordingly speculated that NDEs initially cause negative symptoms that later may evolve into positive changes (e.g., Atwater, 2003; Brumm, 2006; Christian, 2006; Greyson, 2001, 2003; James, 2004; Parnia, Spearpoint, \& Fenwick, 2007). It may even take many years to differentiate between positive growth and psychopathology following NDEs (Parnia, Spearpoint, \& Fenwick, 2007). Based on P. M. H. Atwater's (2003) research on adult and child NDErs, she posited a long integration period involving four distinct phases that can occur post-NDE over a 15-year period. For these reasons, NDErs are particularly vulnerable to labels of psychopathology, despite the fact that research indicates that NDEs are becoming increasingly common and appear to be unrelated to psychopathology (Holden, Long, \& MacLurg, 2009).

How mental health professionals diagnose NDErs may be particularly important, because diagnosis shapes treatment. One established diagnosis fits well the clinical presentation of many NDErs: the $D i$ agnostic and Statistical Manual (DSM-IV; American Psychiatric Association, 2000) category, "Religious or Spiritual Problems." Health professionals' use of this category could minimize the implications of misdiagnosing NDEs as psychopathological, but it has been an underutilized diagnosis (Brown, 2007; Brun, 2005; Herrick, 2006; Lukoff, Lu, \& Turner, 1998; Scott, Garver, Richards, \& Hathaway, 2003), and, too frequently, NDErs are lumped into more conventional psychopathological diagnostic categories that not only fit poorly but can be iatrogenic. For example, despite extensive literature that NDErs frequently do not meet criteria for post-traumatic stress or dissociative disorder diagnoses (Atwater, 2003; Britton \& Bootzin, 2004; Greyson, 1997, 2001, 2003; James, 2004; Parnia et al., 2007; Parnia, Waller, Yeates, \& Fenwick, 2001; Simpson, 2001; van Lommel, van Weiss, \& Efferich, 2001), they often receive such psychopathological diagnoses due to a lack of mental health professionals' understanding of NDEs. 
Having established that it is important for psychologists and other mental health professionals to understand and support NDErs, are these professionals sufficiently knowledgeable and supportive? If not, educational and training programs could rectify deficits. And does openness to transpersonal phenomena relate to mental health professionals' knowledge and supportiveness? If so, increasing openness could be a specific target to guide the design of such programs.

\section{Method}

Consequently, we decided to explore whether psychologists' knowledge and attitudes related to NDEs had changed by comparing Barbara Walker and Robert Russell's 1989 sample of Illinois psychologists with a sample of Washington state psychologists nearly two decades later. We hypothesized that these factors were unchanged, indicating that, despite growing popular awareness of NDEs, psychologists need education and training programs on NDEs. We also hypothesized that psychologists' level of transpersonal self-concept would relate positively to their knowledge and attitudes about NDEs because many aspects of NDEs are transpersonal in nature; if so, this finding could indicate that strategies to enhance transpersonal selfconcept might be relevant in designing future education and training programs on NDEs for psychologists.

We randomly selected 84 participants from a pool of 219 licensed psychologists listed in the National Register of Health Service Providers in Psychology (2008) in the state of Washington and mailed them a survey consisting of two standardized measures and demographic questions. We sent a follow-up mailing 30 days after the first to those who had not yet replied.

We measured psychologists' knowledge and attitudes towards NDEs using Walker and Russell's (1989) Near-Death Phenomena Knowledge and Attitudes Questionnaire (NDPKAQ), a slightly modified version of Nina Thornburg's (1988) questionnaire for healthcare professionals that made it more applicable to psychologists. We obtained permission from Walker and Russell to use this questionnaire. We examined three of its scales: Knowledge, Attitude toward Near-Death Phenomena, and Attitude toward Care. Thornburg's (1988) measure initially demonstrated high internal consistency and reliability as well as content validity by a panel of NDE experts and construct validity by factor analysis. Follow-up studies utilizing Thornburg's scale, however, showed less impressive rates of inter- 
nal consistency and reliability (Cunico, 2001). Walker and Russell's (1989) modified version showed a high rate of internal consistency and reliability for the Knowledge, Attitude toward Near-Death Phenomena, and Attitude toward Care scales through Cronbach alpha reliabilities ranging from .70 to .92 .

We used the Self-Expansiveness Level Form (SELF; Friedman, 1983), in which respondents completed Likert scale items to rate their degree of willingness to identify with various levels of self-concept, from personal to transpersonal. We analyzed only the Transpersonal Scale (TS) that consists of 5 items. The TS measures an expanded sense of self, congruent with unusual phenomena that some NDErs might have experienced. Harris Friedman (1983) found high testretest reliabilities for the SELF-TS with $r=.80$ respectively at two month follow-ups, as well as support for its criterion and construct validity. Douglas MacDonald, Catherine Tsagarakis, and Cornelius Holland (1994) also found high internal consistency values for SELFTS with $r=.79$ and reported favorable criterion and construct validity. More recently, James Pappas and Friedman (2007) further supported the construct validity of the SELF-TS. In addition, previous NDE researchers have used the SELF-TS (Prosnick \& Evans, 2003).

\section{Results}

We compared our data from the NDPKAQ Knowledge, Attitude toward Near-Death Phenomena, and Attitude toward Care scales with data from Walker and Russell's (1989) sample of 115 participants on the same scales, using two-sample $t$-tests for equal means (not assuming equal variances). We used Pearson correlations to analyze whether the SELF-TS was associated with the NDPKAQ Knowledge, Attitude toward Near-Death Phenomena, and Attitude toward Care scales. All analyses were evaluated at the $p<.05$ significance level, the former using two-tailed and the latter one-tailed tests. Effect size indices accompany the reporting of all statistical tests (Cohen, 1998).

We collected data in 2008. Out of 84 questionnaires mailed, 18 participants (21\%) gave complete responses, a small but typical return rate for a mailed survey. Of those responding, $61 \%$ were male and $39 \%$ female; ethnicity was not collected in this sample. Their mean age was 60 years; $94 \%$ held a $\mathrm{PhD}$ and $6 \%$ a PsyD degree. All participants confirmed that they were licensed psychologists in Washington, with $67 \%$ being clinical and 33\% counseling psychologists. All 
participants indicated that, at the time of the study, they provided professional services: $78 \%$ in private practice, $11 \%$ in other settings such as universities, and $11 \%$ in unspecified work settings. All participants indicated they had heard of NDEs, $22 \%$ reported having had an NDE, 56\% reported counseling a client who had reported an NDE, and $44 \%$ reported knowing a family member or friend who had reported an NDE.

The mean NDPKAQ Knowledge scale score for our sample was $6.61(\mathrm{SD}=2.18)$ with a range of $0-18$, which was not statistically different from Walker and Russell's sample $(M=7.5, S D=3.3)$ in a comparison $(t[23]=1.10, p>.05, d=0.32)$. Likewise, the mean score for the Attitude toward Near-Death Phenomena scale in our sample was 63.11 ( $\mathrm{SD}=7.40)$ with a range of $0-85$, again not statistically different from Walker and Russell's sample $(M=61.30, S D=9.5)$ in a comparison $(t[27]=0.92, p>.05, d=-0.21)$. Last, the mean score for the Attitude toward Client Care scale in our sample was 54.78 $(\mathrm{SD}=6.0)$ with a range of $0-75$, again not statistically different from Walker and Russell's sample $(M=53.7, S D=7.4)$ in a comparison $(t[26]=0.69, p>.05, d=-0.16)$. In each of the three results, Cohen's (1988) effect size guidelines indicated a small effect of $d<.5$.

The correlations between scores on the SELF-TS with the NDPKAQ Knowledge scale $(r=.44, p=.03)$ and the NDPKAQ Attitude toward Near-Death Phenomena scale $(r=.40, p=.05)$ were both statistically significant. However, the correlation between scores on the SELF-TS with the NDPKAQ Attitude toward Care scale $(r=.34, p=$ .08) was not statistically significant. Cohen's (1988) effect size guidelines indicated that the magnitudes of these three correlations were medium in size, as they were between .30 and .50 .

\section{Discussion and Conclusion}

Our findings suggest that psychologists' knowledge of and attitudes towards NDEs have remained relatively unchanged in the 20 years since the Walker and Russell (1989) study. We must be tentative in this conclusion for a number of reasons. First, our sample of 18 respondents was small, and the mean age of 60 years seems relatively older than the entire population of psychologists. In addition, our sample was limited to psychologists listed in the National Register of Health-a select group rather than the complete population of Washington psychologists. For all these reasons, our sample may not be representative of psychologists in general, and comparison of them to the larger sample of non-select, Illinois psychologists may lack valid- 
ity. Another possible difference between our sample and Walker and Russell's was that all of our participants had heard of NDEs, nearly a quarter indicated having had an NDE, and a majority had counseled an NDE experiencer; we speculate that our sample may have been biased in a way that, despite their relatively low scores, actually overestimates the knowledge of and positive attitudes toward NDEs of psychologists in general.

The results of comparing the SELF-TS to the NDPKAQ scales reached statistical significance for two out of the three scales examined, and the remaining scale trended in the hypothesized direction. These findings suggest that psychologists higher in transpersonal self-concept tend to be more knowledgeable about and hold more favorable attitudes toward NDEs. In this regard, it is interesting to speculate about the possible role of transpersonal self-concept, as well as other possible moderating variables, that might affect psychologists' acceptance of the importance of NDEs.

The findings from our small study support the need for a larger, perhaps nationwide, study to further assess psychologists' knowledge and attitudes towards NDEs, as well as for the possible need to include other mental health professionals in future studies. We also recommend examining whether psychologists who know less about NDEs actually treat NDErs differently; for example, whether they are more likely to diagnose NDErs with psychopathological disorders or discourage them from openly exploring their NDEs. Our examination of the possible link between transpersonal self-concept and psychologists' knowledge and attitudes towards NDEs also points to the need for additional studies to examine how psychologists' transpersonal beliefs and experiences could impact how they diagnose and treat NDErs. Last, we speculate that encouraging greater openness to transpersonal perspectives could enhance the effectiveness of educational and training efforts on NDEs for mental health professionals. Developing educational and training initiatives for mental health professionals to keep up with technological advances that herald the growing probability of coming into contact with NDErs would logically stem from further research showing these experiences are common and normal, not psychopathological, and may even present NDErs with opportunities for extraordinary psychological growth.

\section{References}

American Psychiatric Association. (2000). Diagnostic and statistical manual of mental disorders (4th ed., text rev.). Washington, DC: Author. 
Atwater, P. M. H. (2003). Our tiniest near-death experiencers: Startling evidence suggestive of a brain shift. Journal of Religion and Psychical Research, 10, 86-97.

Britton, W. B., \& Bootzin, R. R. (2004). Near-death experiences and the temporal lobe. Psychological Science, 15, 254-258.

Brown, J. (2007). Inquiry into the understanding and applications of DSM-IV category religious or spiritual problem, V-code 62.89 by American Psychological Association (APA) psychologists. Dissertation Abstracts International: Section B: The Sciences and Engineering, 67, (7-B), 4097.

Brumm, K. (2006). A study of near-death experiences and coping with stress. Journal of Near-Death Studies, 24, 153-173.

Brun, W. L. (2005). A proposed diagnostic schema for religious/spiritual concerns. Journal of Pastoral Care \& Counseling, 59, 441-454.

Christian, S. R. (2006). Marital satisfaction and stability following a near-death experience of one of the marital partners. Dissertation Abstracts International Section A: Humanities and Social Sciences, 66, (11-A), 3925.

Cohen, J. (1988) Statistical power analysis for the behavioral sciences (2nd ed.). Hillsdale, NJ: Lawrence Erlbaum.

Cunico, L. (2001). Knowledge and attitudes of hospital nurses in Italy related to near-death experiences. Journal of Near-Death Studies, 20, 37-50.

Friedman, H. L. (1983). The Self-Expansiveness Level Form: A conceptualization and measurement of a transpersonal construct. Journal of Transpersonal Psychology, 15, 37-50.

Greyson, B. (1997). The near-death experience as a focus of clinical attention. Journal of Nervous and Mental Disease, 185, 327-334.

Greyson, B. (2001). Posttraumatic stress symptoms following near-death experiences. American Journal of Orthopsychiatry, 71, 368-373.

Greyson, B. (2003). Incidence and correlates of near-death experiences in a cardiac care unit. General Hospital Psychiatry, 25, 269-276.

Hayes, E. R., \& Orne, R. M. (1990). A study of the relationship between knowledge and attitudes of nurses in practice related to the near-death experience. Loss, Grief \& Care, 4, 71-80.

Hayes, E. R., \& Waters, L. D. (1989). Interdisciplinary perceptions of the neardeath experience: Implications for professional education and practice. Death Studies, 13, 443-453.

Herrick, K. E. (2006). Spirituality legitimized . . almost. Journal of Spirituality and Paranormal Studies, 29, 227-236.

Holden, J. M., Long, J., \& MacLurg, B. J. (2009). Characteristics of near-death experiencers. In J. M. Holden, B. Greyson, \& D. James (Eds.), The handbook of near-death experiences: Thirty years of investigation (pp. 109-134). Santa Barbara, CA: Praeger/ABC-CLIO.

James, D. (2004). What emergency department staff need to know about neardeath experiences. Topics in Emergency Medicine, 26, 29-34.

Lawrence, R. M., \& Duggal, A. (2001). Spirituality in psychiatric education and training. Royal Society of Medicine, 94, 303-305.

Lukoff, D., Lu, F., \& Turner, R. (1998). From spiritual emergency to spiritual problem: The transpersonal roots of the new DSM-IV category. Journal of $\mathrm{Hu}$ manistic Psychology, 38, 21-50.

MacDonald, D. A., Tsagarakis, C. I., \& Holland, C. J. (1994). Validation of a 
measure of transpersonal self-concept and its relationship to Jungian and five factor model conceptions of personality. Journal of Transpersonal Psychology, $26,175-201$.

McVoy, M. D. (1990). The near-death experience: Implications for nursing education. Loss, Grief \& Care, 4, 51-55.

Moore, L. H. (1994). An assessment of physicians' knowledge of and attitudes toward the near-death experience. Journal of Near-Death Studies, 13, 91-102.

Morris, L. L. (1998). The nature and meaning of near-death experiences to patients and critical care nurses. Dissertation Abstracts International: Section B: The Sciences and Engineering, 59, (4-B), 1586. Retrieved from the Academic Search Premier database.

Morris, L. L., \& Knafl, K. (2003). The nature and meaning of the near-death experience for patients and critical care nurses. Journal of Near-Death Studies, 21, 139-167. doi:10.1023/A:1021235922301

National Register of Health Service Providers in Psychology (June 14, 2008). Retrieved from http://www.nationalregister.com/osd/search.php?page=4.

Pappas, J., \& Friedman, H. (2007). The construct of self-expansiveness and the validity of the Transpersonal Scale of the Self-Expansiveness Level Form. $\mathrm{Hu}$ manistic Psychologist, 35(4), 323-347.

Parnia, S., Spearpoint, K., \& Fenwick, P. B. (2007). Near-death experiences, cognitive function, and psychological outcomes of surviving cardiac arrest. Resuscitation, 74, 215-221.

Parnia, S., Waller, D. G., Yeates, R., \& Fenwick, P. (2001). A qualitative and quantitative study on the incidence, features, and etiology of near-death experiences in cardiac arrest survivors. Resuscitation, 48, 149-156.

Prosnick, K. P., \& Evans, W. J. (2003). Validity and reliability of the Near-Death Experience Scale-6 (NDE-6). Journal of Near-Death Studies, 22, 133-143.

Scott, S., Garver, S., Richards, J., \& Hathaway, W. L. (2003). Religious issues in diagnosis: the V-code and beyond. Mental Health, Religion \& Culture, 6, 161-173.

Sheeler, R. D. (2005). Teaching near-death experiences to medical students. Journal of Near-Death Studies, 23, 239-247.

Simpson, S. M. (2001). Near-death experience: A concept analysis as applied to nursing. Journal of Advanced Nursing, 36, 520-526.

Thornburg, N. R. (1988). Development of the near-death phenomena knowledge and attitudes questionnaire. Journal of Near-Death Studies, 6, 223-239.

van Lommel, P., van Wees, R., Meyers, V., \& Elfferich, I. (2001). Near-death experience in survivors of cardiac arrest: A prospective study in The Netherlands. Lancet, 358, 2039-2045.

Walker, B. A., \& Russell, R. D. (1989). Assessing psychologists' knowledge and attitudes toward near-death phenomena. Journal of Near-Death Studies, 8, $103-110$.

Wren-Lewis, J. (2004). The implications of near-death experiences for understanding posttraumatic growth. Psychological Inquiry, 15, 90-92.

Zingrone, N. L., \& Alvarado, C. S. (2009). Pleasurable Western adult near-death experiences: Features, circumstances, and incidence. In J. M. Holden, B. Greyson, \& D. James (Eds.), The handbook of near-death experiences: Thirty years of investigation (pp. 17-40). Santa Barbara, CA: Praeger/ABC-CLIO. 